\title{
XXVI. Description of a mechanical instrument to work addition of numbers with accuracy and dispatch
}

\section{Mr.J. Goss}

To cite this article: Mr. J. Goss (1813) XXVI. Description of a mechanical instrument to work addition of numbers with accuracy and dispatch , Philosophical Magazine Series 1, 41:179, 166-171, DOI: $10.1080 / 14786441308638725$

To link to this article: http://dx.doi.org/10.1080/14786441308638725

曲 Published online: 27 Jul 2009.

Submit your article to this journal $[\pi$

Џll Article views: 2

Q View related articles $\sqsubset$ 
right across the centre, and that called $L_{1}$ S Silla has sunk more than sixty fathoms.

It is difficult to say what will be the close of this dread. ful event : it may be hazarded as a conjecture, however, that it will end in the opening up of one or more volcanoes: in the mean time the unfortunate inhabitants of these countries, attached to their native soil, and not wishing to abandon the ashes of their fathers, have with great labour erected rude habitations, in which they await with stoicism and resignation the termination of their caJamities.

J. H. S.

XXVI. Description of a mechanical Instrument to work Addition of Numlers with Accuracy and Disputch. By Mr. J. Goss, of Enfield*.

SIR,-A Bout two years ago I resided at Hatherleigh in Devonshire, where I liad a day-school, and lodged with people whokept a shop: they had frequent occasion to cast up bills, but having but little knowledge of figures were very liable to make mistakes; they therefore, when a bill was any way long, generally brought it to me, and oftentimes, when I have been out in the town, I have been sent for to come home and cast up a bill; at length I thought if some mechanical contrivance could be invented to cast up bills, it would be of great service to many, or even to all who are in business. I knew that multiplication, division, and many other rules in arithmetic, were often worked mechanically; but addition being in itself so irregular, I was afraid no instrument could be invented to work it. However, by repeatedly considering the subject, I discovered after some time a method of casting up a bill by a s!ide rule about two feet long and two inches broad; and as I was studying to bring it to greater perfection, an imperfect idea of this 2ddition-wheel sprung up in my mind, which is a much better method than the former : but thinking the experiment would be attended with expense, and after all perhaps be of no advantage to me, it lay dormant in my mind till about last Michaelmas, at which time I came to London, and a friend of mine got me one of the lists of premiums offered

* From Transactions of the Society for the Encouragement of Arts, Mamifactures, and Commerce, for 1812 . The silver medal of the Society was roted to Mr. Goss for this communication, and the Instrument is pre served in the Society's Repository. 
by the Society of Arts, \&c. published in the year 1809 . After I had read of those honorary and pecuniary rewarls which had been given, and were then offered, my desire to obtain. some mark of the Society's approbation could not be appeased but by possession, and I was detcrmined to carry my idea into execution; I immediately renewed my study of this instrument with increased application.

Casting up bills is what falls to the lot of most people in business, and many who are moderately clever at it often find it a troublesome task before they can place any dependence on their being right; they have need to cast them up two or three times, and even then have often as many different sums, and therefore frequently find themselves much confused and juzzled in the operation: the instrument of my invention in such cases would be very acceptable: it would take the work from the mind, and give it to the hand, which would perform it with greater ease, accuracy, and expedition; a person who can only read figures, may by this help add up a bill with as much accuracy as a mathematician.

The same day I completed my instrument, I showed it to the people with whom I lodged, who as I have already observed were shop-keepers. I wrote a bill, and desired them to cast it up; I then showed them how to do it by my wheel, and desired them to add up the same bill by it, and see if it was right. They then proceeded, and cast it up right by the wheel, when they discovered that they had made a mistake of one shilling in the row of pence, and two shillings in the row of shillings. They were therefore much pleased with my new contrivance, because it was more true and less troublesome than the common way.

This wheel has four circular rows of figures upon its face. The first row which is nearest the teeth on the circumference, denotes pence, the second shillings, and the third and fourth denote the total number of pence or shillings, \&c. Thus, if 67 in the third row should be under the index, if I were casting up pence, I should sce in the first row, 4 under or next before the index, and the next red figure passed over by the index would be 5 , which siguify $5 \mathrm{~s} .4 d$., the red figure or figures nearest the index signifying shillings, and the black figure or figures before the index the odd pence. In the second row, the black figure before the index signifies the number of odd shillings, and the next red figure the number of pounds. Before I begin to work, the red figures $360,180,9,15$, must always be placed next before the index. I then begin to cast $\mathrm{L} 4$ 
up the row of pence. If I should have $5 s .4 d$. I set dowh the $4 d$. under the bill, and bring back the red figures 360 , \&c. again before the index; then, with the brass handle 1 move round the wheel 5 divisions, and go on win the row of shillings, $8 \mathrm{cc}$.

This addition-wheel has cost me much time and thought; but should it be honoured with the approbation of the 80 ciety, I shall feel nivself mnch gratified.

$$
\begin{aligned}
& \text { I am, sir, } \\
& \text { Your humble servañt, }
\end{aligned}
$$

No. 4, Wood-Street, Spa-fields, Jan, 21, 1812.

J. Goss.

To C. Taylor, M.D. Sec.

Reference to the Engraving of Mr. J. Goss's Instrument to work the Addition of Numbers in Arithmelic. Plate V. Fig. 1, 2, 3, 4.

This instrument consists of a briss hoop, fixed to a flat circular plane of wood; this hoop is divided on its upper edge into 180 ratchet or saw-like teeth, and the circle has a number of radii lines of figures upon its face, in divisions corresponding with the teeth; also of a supporting cirole, having a fixed index reaching across those lines of figures; and a circular row of 20 divisions, and another of 50 , correspondent to the ratchet teeth; and of a brass central index which takes into the tecth, and will turn the ring in one direction only, to one certain place or stop; and then, the numbers on the circle, close to the fixed index, will show the sum total of the different numbers to which it has been turned round, at any number of intervals. Fig. 1 . is a plan, showing a portion of the moveable hoop and circle, and the numbers which are upon its face. Fig. 2. is a section of the instrument, answering to the same. Fig. 3 . is a plan, on a smaller scale, of the instrument on the under side; and fig. 4. an edge view corresponding with it; the same letters of reference are used in all the figures. AA represents the principal upper or moveable circle, on which some of the numbers are marked; this is attached by a centre pin $R \cdot$ to another circle $\mathrm{BB}$, figs. 2, 3, and 4 , which is held in the hand when the instrument is used; these two circles turn round freely upon each other, and upon the centre of the upper one a radial lever, or index, $\mathrm{CL}$, is fixed, which has a free motion round the centre in $R$. The circle $A A$ has a ring or hoop of brass $M M$, fixed round its circumference, which is cut into 180 serrated teeth, as shown in fig. 2 . The 
centre index CL slips over the sloping side of these teeth when moved in one direction; but when moved in the other, its edge $c$ catches into the perpendicular sides of the terth, and warries the circle round with it. EE, fig. 3, are two brass cocks, screwed to the side of the lower circle $\mathbf{B B}$, and projecting from it beyond the circumference $\mathbf{M}$ of the upper circle; the ends of them support a flat circular wooden or brass limb, FF, which (as shown in fig. 1.) haş other correspondent divisions and figures upon it, over which the index passes: at one end of the limb a wire stop, $b$, is fixed; and when the index is pressed against this, its edge $c$ will stand upon the figure 1. of the limb FF, which is numbered on progressively, $1,2,3,4,5,6$, \&c. to 50; which numbers are the same distance apart as the teeth upon the edge of the great circle $A$; so that, by moving the index to any of these numbers, its edge $C$ will have passed over the samie number of teeth of the circle, as the number of the limb which it is carried to denotes; but in passing in that direction it slips over the sloping edges of the teeth without moving the circle: now, the edge $C$ having arrived at any intended number, as 19 , for instance, the edge of the lever is pressed into the teeth; and being brought back again till it touches the stop $b$, it will have moved the circle A round 19 teeth. At the extreme end of the limb FF, a piece of brass, PP, is fixed, so as to form a reading-index for the numbers on the several circles, which are described on the face of the great circle AA: these are four in number, viz. one for the pence, one for the shillings, and two circles for the pounds : the external circle, which is the pence, is numbered $1,2,3,4,5,6,7,8,9,10,11$, then 1 , marked in red, to denote 1 shilling ${ }^{*}$ : then $1,2,3$, $4,5,6,7,8,9,10,11$, again, and 2 , in red, to denote 2 shillings, and so on, up to 180 , which will be 15 shillings: the next circle towards the centre is for the pounds, this is numbered $1,2,3,4,5,6$, \&c. up to 19 , then one, in red, for one pound: then 19 numbered successiyely again, and 2 in red, for two pounds, and so on till 9 pounds, which fills the circle, because 9 pounds contain 180 shillings : the third circle towards the centre is for the addition of pounds, or any other whole numbers : the circle therefore is numbered in regular ascending series, from 1 to 180 ; but to enable the instrument to count higher than 180, the fourth circle is introduced: this begins at 181 , and proceeds, by a regular increase, to 360 ; $G$, figs, 3 and 4 , is a detent,

* Those figures, which in the instrument are marked in red, the engraver has distinguished by including them in a small circle.

moveable 


\section{Meshanical Instrument to work Addition of Numlers.}

moveable on a centre pin attached by a stud $\mathrm{H}$ to the lower circle $\mathrm{BB}$, and its tail is pressed by a small spring $h$, which causes it to press constantly upon the under side of the great circle $A A$, and produces such a friction as preveats the upper circle slipping loosely round; a screw $k$, fig. 3 , is fixed in one part of the under side of the lower circle, so that in turning round it intercepts the detent $G$, and in this position the edge of the index $P P$ is at the zero, or point of commencement of all the numbered circles. In this position the instrument is ready for use, in the following manner: suppose the following sum is to be added up:

\begin{tabular}{ccc}
$E . s$. & $d$. \\
23 & 14 & 3 \\
18 & 5 & 2 \\
12 & 3 & 4 \\
47 & 6 & 5 \\
21 & 4 & 3 \\
12 & 3 & 4 \\
\hline 134 & 16 & 9
\end{tabular}

Iaving adjusted the instrument as before described, that is, having brought the circle to the zero, bold the circle $B B$ in the one hand, and take the end $I$, of the lever $C L$ in the other: then move the end of the lever CL till jts edge $c$ cuts the figure 4 of the limb FF, which is the first figure in the sum : in this movement the index is held up so as not to touch the teeth; but having arrived at the intended ligure, it is pressed down into the teeth, and is brought back again (the circle with it) until it touches the stop $\vec{b}$, when it will have moved the circle, sa that 4 stands before the index $\mathrm{P}$ on the pence circle; then the index $\mathrm{L}$ is carried back again to 3 , the second figure of the sum, and returned to its stop, carrying with it three divisions more; it is next moved to 5 , and so on, following the pence column till the number 3 at the top is counted; then, examining at the edge of the index PP, it will be found to stand at 9, in the pence circle, and the nearest red figure which has passed by the index will be 1 , denoting 1 shilling and 9 pence; therefore 9 must be put down, and 1 carried to the next column: and to recollect this, a small pin, $x$, must be stuck into the bole No. 1 , upon the outside of the limb F : the circle is then returned to the zero, which is readily performed by turning it backwards as far as it will go, and the stop $k$, fig. 3, prevents its going further than the right position : the column of shillings is then added up by the same process, taking the numbers 3 , 
$4,6,3,5,14$, by successive steps of the index $L$ : then, on examination of the stcond or shilling column, 16 will be found beneath the index, and the nearest red figure which it has passed by will be 1 , denoting 1 pound 16 shillings: 16 therefore is sct down, and the pin $x$ still kept in the same hole to denote that one is carried forwards; the circle Is again brought to the zero, by bringing it back as far as it will go; and lasily, the column of pounds is added, in exactly the same manner.

XXVIT. Disstrtation on the Paintings of the middle Age, and those called Gothic. Extracted from an unpullished Wort on Painting, by M. Paillot de Montabert.

[Continued from p. 44.]

Of the various Schools of the middle Age.-Roman School of the middle Age.-Greek Schoul of Constantinople from the ninth to the sixteenth Century exclusively.-Florentine School of the middle Age.-Venetian School of the middle Age.-Gothic School of the North.

\section{Roman School of the middle Age.}

C Constantinople for a long period gave laws to Europe in the arts; but in spite of the influence which this school may have had over the painters of Rome, the ancient models, always reviving in this rich capital of the world, presented nourishment too abundant and ton wholesome to encourage a preference for the new style of paintings sent from the East, to which they conformed occasionally merely out of condescension. All the artists of Rome, in short, down to the time of Raphael, knew how to profit by the innumerable sculptures and subterranean paintings which were daily discovered in that famous city. There cannot be a doubt, therefore, that the character of this school consisted at all times in a correct style, in clear and expressive pantomimes, forcible and yet agreeable, as well as in draperies of a grond taste; and we ought therefore to regard this school as the first preserver of the true ancient style of painting *.

Greek

- All the Christian sarcophagi of Rome are executed exactly in the style of the last sculptures of Pagatism: and it is ourprising enough to see upon these sepulchral ornaments Moses striking the rock, Jesus entering into Nazareth, or standing in the midst of his apostles, and so many other sacred subjects, similar in the costume and workmanship to the represent;- 